\title{
Semiconductor Zn0 Nano-Rods Thin Film Grown on Silver Wire for Hemoglobin Biosensor Fabrication
}

\author{
I. K. Battisha ${ }^{1}$, H. A. Wahab' , A. A. Salama2 ${ }^{2}$ A. A. El Saeid ${ }^{2}$, M. Willander ${ }^{3}$, 0. Nur ${ }^{3}$ \\ ${ }^{1}$ Solid State Physics Department, Physics Division, National Research Centre (NRC), Dokki, Egypt \\ ${ }^{2}$ Physics Department, Al-Azhar University, Cairo, Egypt \\ ${ }^{3}$ Department of Science and Technology, Campus Norrköping, Linköping University, Norrköping, Sweden \\ Email: szbasha@yahoo.com, ibattisha@gmail.com
}

Received 19 January 2015; accepted 9 February 2015; published 15 February 2015

Copyright (C) 2015 by authors and Scientific Research Publishing Inc.

This work is licensed under the Creative Commons Attribution International License (CC BY). http://creativecommons.org/licenses/by/4.0/

(c) (i) Open Access

\begin{abstract}
Wurtzite hexagonal ZnO semiconductor nano-rods (NRs) thin films were grown on silicon substrates and silver wire with diameter equal $68 \mathrm{~nm}$. Sol gel (SG) and aqueous chemical growth (ACG) methods by two steps of preparation (seed layers and nano-rod growth) are used for samples preparation. The structural and morphological properties are evaluated using X-ray diffraction (XRD) and scanning electron microscope (SEM). The proposed iron ion sensor has shown good linearity for a wide concentration range from $0.078 \mathrm{M} / \mathrm{L}$ to $0.26 \mathrm{M} / \mathrm{L}$ of iron ions. The results show that the electrode is highly sensitive to iron ions with a slope around $47.8 \mathrm{mV} /$ decade with a regression coefficient $R^{2}=0.96$.
\end{abstract}

\section{Keywords}

ZnO Nano-Rods, Thin Films, Sol-Gel, X-Ray Diffraction, Scanning Electron Microscope and Hemoglobin Biosensor

\section{Introduction}

Biosensors development and production are currently expanding due to the recent application of several new techniques, including some derived from physical chemistry, biochemistry, thick- and thin-film physics, materials science and electronics. Biochemical sensors are often simple and can offer real-time analysis of human body analytes. They represent a broad area of emerging technologies ideally suited for human health care analysis.

${ }^{*}$ Corresponding author.

How to cite this paper: Battisha, I.K., Wahab, H.A., Salama, A.A., El Saeid, A.A., Willander, M. and Nur, O. (2015) Semiconductor ZnO Nano-Rods Thin Film Grown on Silver Wire for Hemoglobin Biosensor Fabrication. New Journal of Glass and Ceramics, 5, 9-15. http://dx.doi.org/10.4236/njgc.2015.52002 
All human beings have natural sensing specific systems such as skin as a feelings sensor, ears are hearing sensor, eyes are light (colors) sensor, nose is olfaction and tongue is gestation sensor. Advancement in science and technology has enabled biosensor to be used in variety of function, including medicine, food industry, and environmental science [1] [2]. Traditional chemical and biological analytical techniques used in various fields involve reactions that take place in solutions on addition of reagents or other bio-reactive species. In some systems these reactions take place at an electrode and they are commonly called sensors [3]-[5].

By definition, sensor is a device that detects or measures a physical property and records it; indicating its presence or responds to it in some other way. Usually sensors are composed of an analyte-selective interface, which is connected to or close to a transducer. A transducer is a device that converts an observed change (physical or chemical) into a measureable signal [6]-[8].

\section{Experimental}

$\mathrm{ZnO}$ nano-rods thin film were prepared in two stages (seed solution and nano-rod growth) by using sol-gel (SG) and aqueous chemical growth (ACG) methods, respectively [9]-[11].

\subsection{Seed Solution Prepared by Sol-Gel Method}

To obtain the desired morphology and good quality of the material, the substrate was cleaned prior to nano-crystal $\mathrm{ZnO}$ thin film deposition as reported previously by our team work [12]. The seed solution was used for the surface modification of substrate which, provides nucleation sights for the growth of nano-structures and helps to enhance the density as well as homogeneity of particles [13]. A coating seed solution was prepared by dissolving zinc acetate dehydrate $\left(\mathrm{Zn}\left(\mathrm{CH}_{3} \mathrm{COO}\right)_{2} \cdot 2 \mathrm{H}_{2} \mathrm{O}\right)$ in mixed Solution of MEA $\left(\mathrm{NH}_{2} \mathrm{CH}_{2} \mathrm{CH}_{2} \mathrm{OH}\right)$ and 2-methoxyethanol at room temperature, however the molar ratio of MEA to zinc acetate was 1:1. The seed solution was stirred at $50^{\circ} \mathrm{C}$ for $2 \mathrm{~h}$ until yielding a clear and homogeneous solution. The mixed solutions were aged at room temperature for another $24 \mathrm{~h}$. Then, the solution was coated on the silicon substrate by spin coating with a speed of $3000 \mathrm{rpm}$ for $30 \mathrm{sec}$. The same solution was coated on the silver wire $(0.25 \mathrm{~mm}$ in diameter) by a simple dip coating method to obtain nano-crystalline $\mathrm{ZnO}$ (seed layers) on both surfaces. The coating process was repeated several time and dried in open air at room temperature and finally placed in pre-heated laboratory oven at $250^{\circ} \mathrm{C}$ for annealing in order to decompose the zinc acetate dehydrate into ZnOnano-particles. In addition the seed solution provides a good control on the alignment and density of the nucleation points that affect the diameter of the synthesized nano-structures.

\subsection{Growth Method}

After uniformly coating the silicon substrate and silver wire with ZnO prepared by seed layers, ZnO (NRs) were grown on it using aqueous chemical growth (ACG) method at low temperature. The growth of ZnO nano-rods was achieved by immersing $\mathrm{ZnO}$ seed-layer in $150 \mathrm{~mL}$ of aqueous solution composed of $0.025 \mathrm{M}$ zinc nitrate $\left(\mathrm{Zn}\left(\mathrm{NO}_{3}\right)_{2}\right)$ and $0.025 \mathrm{M}$ hexamethylenetetramine (HMT, $\left.\mathrm{C}_{6} \mathrm{H}_{12} \mathrm{~N}_{4}\right)$ in a conventional flask. The reaction temperature was kept at $90^{\circ} \mathrm{C}-95^{\circ} \mathrm{C}$ for $3-6 \mathrm{~h}$. The position of the substrate inside the solution does affect much on the growth process; however, substrate is being placed in the solution with face toward the bottom of the beaker. Finally, the substrate were removed from the solution, then immediately rinsed with de-ionized water to remove any residual salt from the surface and dried in air at room temperature. The resulting $\mathrm{ZnO}$ (NRs) structure was characterized by X-ray diffraction (XRD) and scanning electron microscope (SEM), respectively.

\subsection{Cover ZnO(NRs) with Ionophor Membrane}

For extracellular iron ions measurements, the $\mathrm{ZnO}(\mathrm{NRs})$ on silver wire were coated with a thin layer of ionophore membrane by manual procedure. The ionophore membrane was prepared by the following composition, 18-crown-6(18CE6) [Fluka], it was used for iron ion selectivity, While Dioctyl phenylphosphonate (DOPP) [Aldrich] was used as plasticizer. Polyvinylchloride (PVC) [Fluka] was used as the membrane matrix and tetrahydrofuran (THF) [Flika] was used as solvents.

After preparing the ionophore solution, the $\mathrm{ZnO}$-coated silver wire dipped two times in it for 5 minutes until a thin film of the membrane was attached to the surface of the $\mathrm{ZnO}$ coated silver wire and then drying it for $1-2$ hours at room temperature. Generally all the sensors were kept at $4{ }^{\circ} \mathrm{C}$ when not in use. The proposed $\mathrm{Fe}^{3+}$ 
sensors were used as working electrode for the potentiometric measurements in an aqueous solution of hemoglobin with a concentration ranging from $0.078 \mathrm{M}$ to $0.26 \mathrm{M}$. An $\mathrm{Ag} / \mathrm{AgCl}$ was acting as a reference electrode. The output voltage of this experiment for each concentration of hemoglobin solution was recorded by using $\mathrm{pH}$ meter (model 3510 Metrohm)

\section{Characterization Techniques}

X-ray diffraction (XRD) patterns were recorded by using a Philips X-ray diffractometer using monochromatic $\mathrm{CuK}_{\alpha 1}$ radiation of wavelength $\lambda=1.5418 \AA$ from a fixed source operated at $40 \mathrm{kV}$ and $30 \mathrm{~mA}$. The crystallite size $(G)$ is determined from the Scherrer's equation $G=K \lambda / D \cos (\theta)$, where $K$ is the Scherer constant $(0.9), \lambda$ is the wavelength and D is the full width (in radians) of the peak at half maximum (FWHM) intensity.

The correction of the measured FWHM (Ds) for a sample peak was made to accommodate systemic instrumental broadening and utilized peak widths (D) measured from a diffraction scan, taken under identical conditions, from a strain-free powdered quartz sample, with crystallite size ranging between 5 and $10 \mu \mathrm{m}$. The corrected sample peak widths were calculated as $\mathrm{D}=\left(\mathrm{Ds}^{2}-\mathrm{Dq}^{2}\right)^{1 / 2}$ Micro-strain and crystallite size contributions to $\mathrm{D}$ were separated using the Win-Fit program, using standard samples for estimation of instrumental broadening. The final sample crystallite sizes $(G)$ were obtained by Fourier analysis, using the corrected profile. The diffraction peak used was the most intense diffraction peak, assigned to the (002) reflection from the $\mathrm{ZnO}$ thin film.

The coarse and fine microstructures of the prepared samples were depicted by Field Emission Scanning electron microscope (FESEM).

The coarse and fine microstructures and the morphology of all the ZnO NRs were depicted by using JEOL JSM-63o1F scanning electron microscope (SEM). The SEM gives information on the surface morphology of the sample, which can helps us check whether the growth has taken place or not. The SEM produced 2 D image and reveals topographic filature of the sample, which allow us to examine the diameter, length, shape and density of the ZnO NRs.

\section{Results and Discussion}

\subsection{X-Ray Diffraction (XRD)}

The crystal structure of ZnO (NRs) thin films were identified by X-ray diffraction (XRD before and after the formation of nano-rods

X-rays diffraction patterns shown in Figure 1 (a) for seed layer annealed at $250^{\circ} \mathrm{C}$ while Figure 1 (b) is of ZnOnano-rods after growth. The figures endorsed the growth orientations and crystal structure of ZnO (NRs) thin films by revealing emission peaks at $2 \theta^{\circ}$ equal to $32,34.5,36.5,47$ and $56.6^{\circ}$, corresponding to (100), (002), (101), (102), (110), (103) and (112) orientations, respectively. However no diffraction peaks of other impurities were detected, which testify that the substance deposited on the substrate only belongs to $\mathrm{ZnO}$. All diffraction peaks can be indexed to $\mathrm{ZnO}$ with the hexagonal wurtizite structure, and compatible with the standard card of bulk ZnO with hexagonal structure, Card number [01-089-1397].

Figure 1(b) of $\mathrm{ZnO}$ (NRs) thin film shows stronger and sharper diffraction peaks due to the increase in film thickness corresponding to the (002) crystal plan of $\mathrm{ZnO}$ as principle peak and all other peaks indicated that the orientation growth of nano-rods along the $\mathrm{C}$-axis direction of $\mathrm{ZnO}$ crystal is perpendicular to the substrate.

\subsection{Scanning Electron Microscope (SEM)}

The surface morphology, dimensionality and density of the ZnO (NRs) thin film was investigated by Field Emission Scanning electron microscope (FESEM). Figure 2 shows a panoramic view of the ZnO (NRs) grown on silicon substrate covering the whole area with uniform density. Smoothness of the top surface, equal length and vertically aligned along the c-axis (perpendicular to the substrate), which corresponds well with the obtained result from XRD pattern was detected.

Figure 3(a) and Figure 3(b) shows the morphological and structure information about the ZnO (NRs), prior and after the coating with iron membrane, obtained by FESEM. Figure 3(a) shows a low magnification ZnO (NRs) FESEM image grown on silver wire before coating with iron membrane. It can be seen that the entire Ag wire is covered with $\mathrm{ZnO}$ (NRs) at uniform density along the near perpendicular direction to the surface of the 


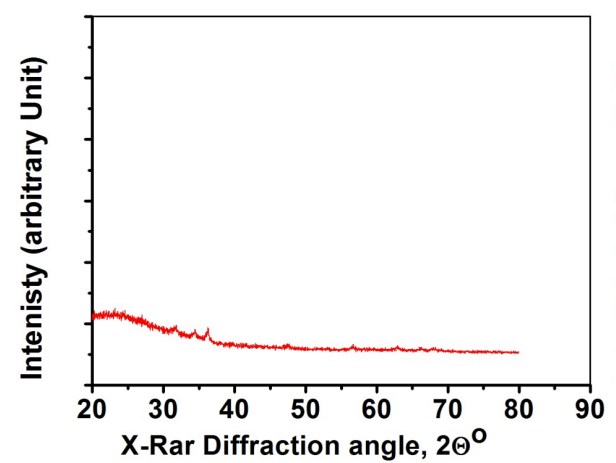

(a)

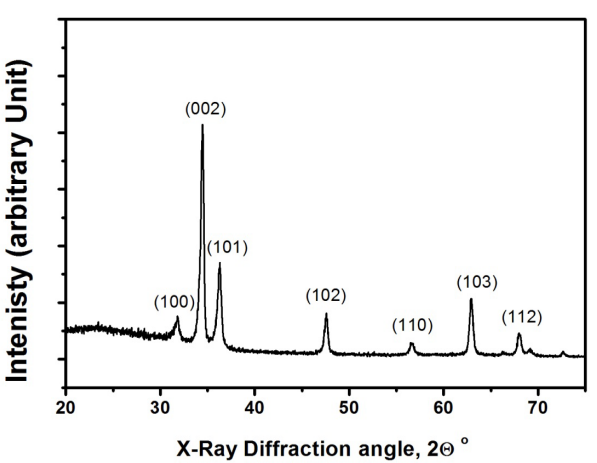

(b)

Figure 1. X-Ray Diffraction of ZnOthin films deposited on silicon substrate: (a) Nanoparticles (seed layer) prepared by spin coatingsol gel method (b) Nanorods prepared by aqueous chemical growth.

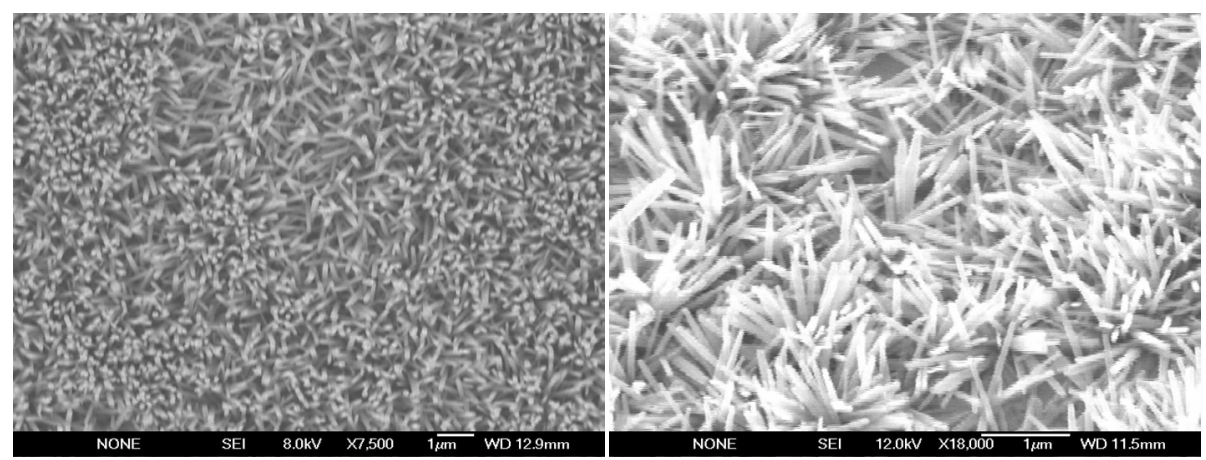

Figure 2. High Resolution scanning electron microscopy (FESEM) images of ZnOnano_rods grown on silicon substrate.

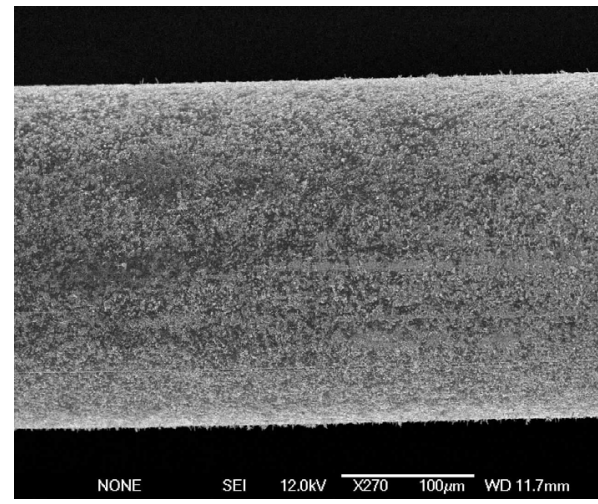

(a)

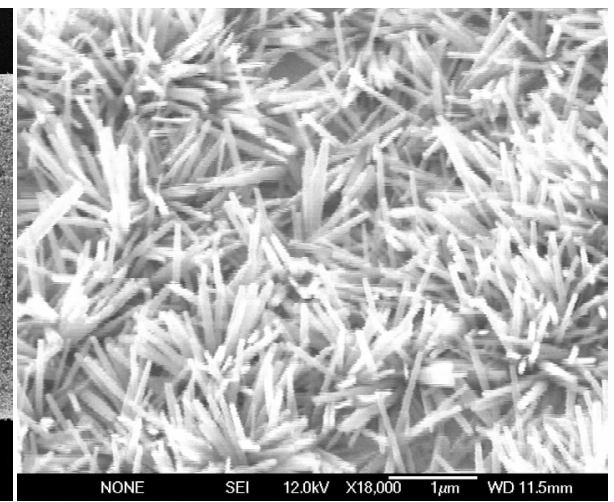

(b)

Figure 3. (a) and (b) High Resolution scanning electron microscopy (FESEM) images of ZnO nano-rods thin film grown on silver wire $(0.25 \mathrm{~mm}$ in diameter) with different magnifications before coating with iron membrane, using low temperature Aqueous Chemical Growth) method.

Ag wire. The highly magnified SEM image shown in Figure 3(b) displays the hexagonal shape and was found to be vertically aligned and distributed uniformly with an average diameter of (60 - $95 \mathrm{~nm})$.

Figure 4 shows a typical scanning electron microscopy (FESEM) image of $\mathrm{ZnO}$ (NRs) grown on silver wire ( $0.25 \mathrm{~mm}$ in diameter) after coating with iron membrane. It has indicated that the membrane covers all surface of the film. 


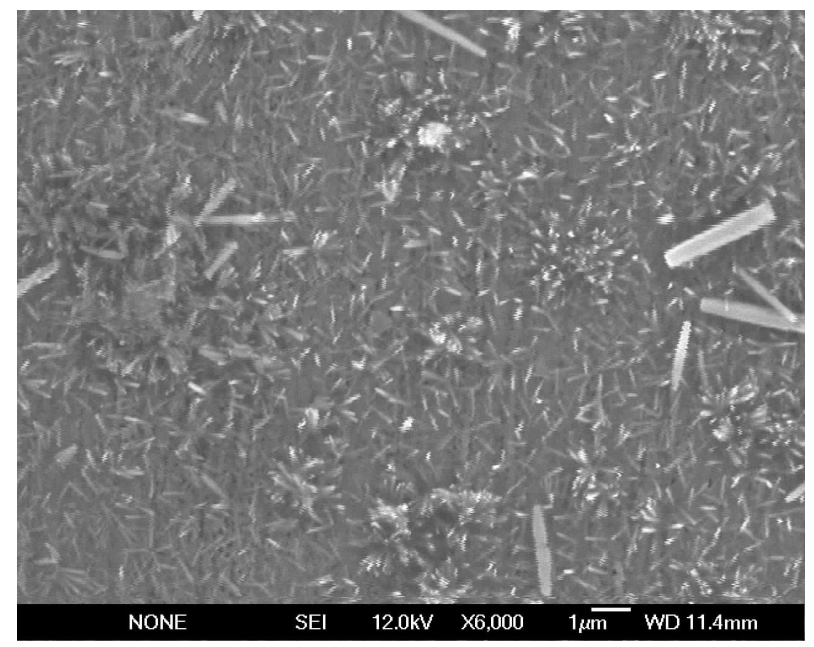

Figure 4. High Resolution scanning electron microscopy (FESEM) images of $\mathrm{ZnO}$ nano-rods thin film grown on silver wire $(0.25 \mathrm{~mm}$ in diameter) after coating with iron membrane, using low temperature Aqueous Chemical Growth) method.

\subsection{Zinc Oxide Nano-Rods with Ionophore-Membrane Coating as an Extracellular $\mathrm{Fe}^{3+}$ Selective Hemoglobin Sensor}

We used our sample to study iron ion selectivity of $\mathrm{ZnO}$ (NRs) sensors using ionophore membrane coatings. The potentiometric response of the $\mathrm{Fe}^{3+}$ ions was studied in aqueous solutions of Hemoglobin with concentration ranging from $0.078 \mathrm{M}$ to $0.26 \mathrm{M}$.

The electrochemical cell voltage (electromotive force) changes when the composition of the test electrolyte was changed. These changes can be related to the concentration of ions in the test solution via a calibration procedure.

The construction of the cell potential of the developed $\mathrm{Fe}^{3+}$ sensor presented here can be shown by the diagram bellow:

The cell voltage is a function of the concentration of the testing electrolyte solution. This means that the voltage changes due to the change in concentration of iron ions in the testing solution. We checked the response of the functionalized $\mathrm{ZnO} \mathrm{Fe}{ }^{3+}$ electrode into $0.078 \mathrm{M} / \mathrm{L}$ to $0.26 \mathrm{M} / \mathrm{L}$, it was observed that the $\mathrm{Fe}^{3+}$ sensor showed very stable output voltage for this concentration range. This is shown in the calibration curve of the logarithm concentration of $\mathrm{Fe}^{3+}$ versus the output voltage response.

Figure 5 shows the calibration curve of the logarithm concentration of $\mathrm{Fe}^{3+}$ in aqueous solution of Hemoglobin versus the output voltage response by using silver wire as a sensor

The proposed iron ion sensor has shown good linearity for a wide concentration range from $0.078 \mathrm{M} / \mathrm{L}$ to 0.26 $\mathrm{M} / \mathrm{L}$ of iron ions. The results show that the electrode is highly sensitive to iron ions with a slope around 47.8 $\mathrm{mV} /$ decade with a regression coefficient $\mathrm{R}^{2}=0.96$.

\section{Conclusion}

The sol gel and aqueous chemical growth methods were successfully used in the two steps $\mathrm{ZnO}$ (NRs) thin films preparation. The prepared films have Wurtzite hexagonal structure as revealed from XRD analysis. The ZnO (NRs) grown on glass substrate and silver wire were found to be vertically aligned and distributed uniformly with an average diameter of (60 - $95 \mathrm{~nm}$ ). The potentiometric response of the $\mathrm{Fe}^{3+}$ ions was studied in aqueous solutions of Hemoglobin with concentration ranging from 0.078 M to 0.026 M. The presented iron biosensor based on $\mathrm{ZnO}$ (NRs) on Ag wire provides substantial advantage due to its smaller size, cost efficiency and its easy fabrication. We used our samples to study iron ions electivity of $\mathrm{ZnO}$ (NRs) sensors using ionophore membrane coatings. The calibration curve of the logarithmic concentration of $\mathrm{Fe}^{3+}$ in Hemoglobin aqueous solution versus the output voltage response by using silver wire as a sensor, shows good linearity for a wide concentration range from $0.078 \mathrm{M} / \mathrm{L}$ to $0.26 \mathrm{M} / \mathrm{L}$ of iron ion in the Hemoglobin aqueous solutions. The results showed that the 


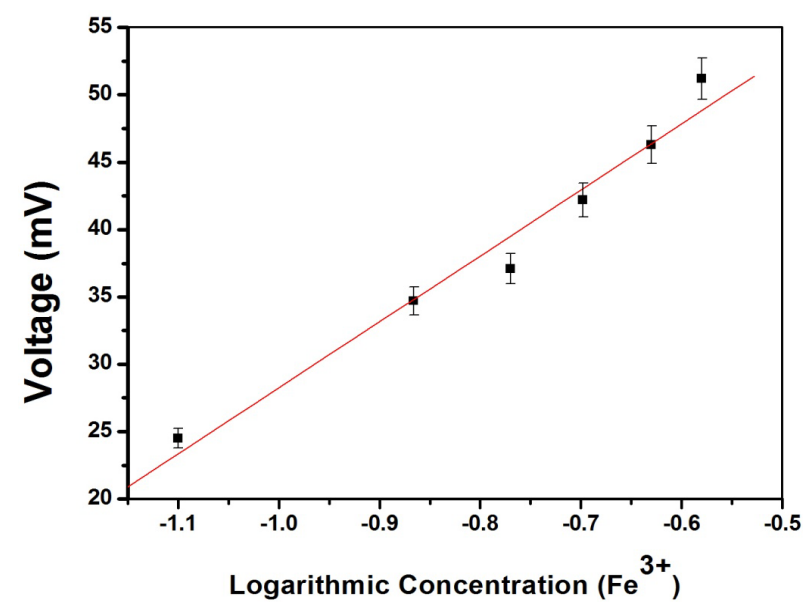

Figure 5. Calibration curve showing the electrochemical potential difference, for the silver wire $\mathrm{ZnO}$ (NRs) as potentiometric electrode with $\mathrm{Ag} / \mathrm{AgCl}$ reference electrode versus Logarithmic concentration range for $\mathrm{Fe}^{3+}$ change for Hemoglobin solution.

electrode is highly sensitive to iron ions with a slope around $47.8 \mathrm{mV} /$ decade with a regression coefficient $\mathrm{R}^{2}=$ 0.96 .

\section{Acknowledgements}

The authors acknowledge the STDF project ID: 5368 for supporting this work.

\section{References}

[1] Ali, S.U., Ibupoto, Z.H., Salman, S., Nur, O., Willander, M. and Danielsson, B. (2011) Selective Determination of Urea Using Urease Immobilized on ZnO Nanowires. Sensors and Actuators B: Chemical, 160, 637-643. http://dx.doi.org/10.1016/j.snb.2011.08.041

[2] Ali, S.U., Kashif, M., Ibupoto, Z.H., Alam, F., Hashim, U. and Willander, M. (2011) Functionalised Zinc Oxide Nanotube Arrays as Electrochemical Sensors for the Selective Determination of Glucose. Micro \& Nano Letters, 6, 609-613. http://dx.doi.org/10.1049/mnl.2011.0310

[3] Dev, A., Panda, S.K., Kar, S., Chakrabarti, S. and Chaudhuri, S. (2006) Surfactant-Assisted Routeto Synthesize WellAligned ZnO Nanorod Arrays on Sol-Gel-Derived ZnO Thin Films. The Journal of Physical Chemistry B, 110, 1426614272. http://dx.doi.org/10.1021/jp0627291

[4] Fulati, A., Ali, M.U., Asif, M.H., Alvi, N. ul H., Willandera, M., Brännmark, C., Strålfors, P., Börjesson, S.I., Elinder, F. and Danielsson, B. (2010) An Intracellular Glucose Biosensor Based on Nanoflake ZnO. Sensors and Actuators B: Chemical, 150, 673-680. http://dx.doi.org/10.1016/j.snb.2010.08.021

[5] Wahab, H.A., Nur, O., Willander, M., Salama, A.A., El Saeid, A.A. and Battisha, I.K. (2014) Growth of Zinc Oxide (ZnO) Nano-Rod Thin Film for Hemoglobin Biosensor Applications Prepared Using Sol-Gel and Aqueous Chemical Growth. International Journal of Engineering and Innovative Technology (IJEIT), 4, 6-13.

[6] Asif, M.H., Ali, M.U., Nur, O., Willander, M., Brannmark, C., Stralfors, P., Englund, U.H., Elinder, F. and Danielsson, B. (2010) Functionalised ZnO-Nanorod-Based Selective Electrochemical Sensor for Intracellular Glucose. Biosensors and Bioelectronics, 25, 2205-2211. http://dx.doi.org/10.1016/j.bios.2010.02.025

[7] Khun, K., Ibupoto, Z.H. Ali, S.U., Chey, C.O., Nur, O. and Willander, M. (2012) Iron Ion Sensor Based on Functionalized ZnO Nanorods. Electroanalysis, 24, 521-528.

[8] Kim, Y.H., Baek, N.S., Kim, K.H. and Jung, S.-D. (2012) Simplifying Patterning Process of ZnO Nanowires by One Step Development and Etching Process. Journal of Sol-Gel Science and Technology, 64, 304-308. http://dx.doi.org/10.1007/s10971-012-2858-8

[9] Tsaya, C.-Y., Fan, K.-S., Chen, S.-H. and Tsai, C.-H. (2010) Preparation and Characterization of ZnO Transparent Semiconductor Thin Films by Sol-Gel Method. Journal of Alloys and Compounds, 495, 126-130. http://dx.doi.org/10.1016/j.jallcom.2010.01.100

[10] Yin, Y.T., Que, W.X. and Kam, C.H. (2010) ZnO Nanorods on ZnO Seed Layer Derived by Sol-Gel Process. Journal 
of Sol-Gel Science and Technology, 53, 605-612.

[11] Zak, A.K., Abrishami, M.E., Abd. Majid, W.H., Yousefi, R. and Hosseini, S.M. (2011) Effects of Annealing Temperature on Some Structural and Optical Properties of ZnO Nanoparticles Prepared by a Modified Sol-Gel Combustion Method. Ceramics International, 37, 393-398. http://dx.doi.org/10.1016/j.ceramint.2010.08.017

[12] Wahab, H.Z., Salama, A.A., El-Saeid, A.A., Nur, O., Willander, M. and Battisha, I.K. (2013) Optical, Structural and Morphological Studies of (ZnO) Nano-Rod Thin Films for Biosensor Applications Using Sol Gel Technique. Results in Physics, 3, 46-51. http://dx.doi.org/10.1016/j.rinp.2013.01.005

[13] Liu, Z.F., Ya, J. and Lei, E. (2010) Effects of Substrates and Seed Layers on Solution Growing ZnO Nanorods. Journal of Solid State Electrochemistry, 14, 957-963. 